UDK: 711.5:502.15

DOI: https://doi.org/10.24867/14FA05Rondic

\title{
STUDIJA PRIJEPOLJA KROZ ISTORIJU I TRANSFORMACIJA PARKA NARODNIH HEROJA
}

\section{STUDY OF PRIJEPOLJE THROUGH THE HISTORY AND TRANSFORMATION OF THE PARK OF PEOPLE'S HEROES}

\author{
Šejla Rondić, Darko Reba, Fakultet tehničkih nauka, Novi Sad
}

\begin{abstract}
Oblast- ARHITEKTURA I URBANIZAM
Kratak sadržaj - Prijepolje se u istorijskim dokumentima prvi put spominje 1332.godine, a spominje ga putopisac i diplomat Adam Gijom pišući o starim varošima $i$ rudarskim mjestima. Međutim, Prijepolje se u dostupnim pisanim spomenicima prvi put javlja u ugovoru koga su Dubrovčani 7. jula 1343. godine zaključili s Arbanasima Burmazima o prenosu 100 tovara soli u trg manastira Mileševo u mestu zvanom »Prijepolje«. „Razvoju Prijepolja kao trga u značajnoj meri, između ostalog, doprineo je $i$ njegov povoljan geografski položaj na raskrsnici puteva iz doline Lima preko Sjenice i Trgovišta prema Novom Brdu, Prištini, Trepči, i dalje prema Sofiji i Istanbulu. Drugi deo puta išao je preko Višegrada, Goražda, Foče do Dubrovnika. Prijepolje nije bilo samo karavanska stanica u klasičnom smislu, odnosno mesto konačišta i odmora ljudi i konja nakon napornog puta. Tu su se sastajali trgovci i ponosnici, obavljani razni trgovački poslovi i isplaćivani ugovorni iznosi za razni prenos roba [5].
\end{abstract}

Klučne reči: istorija, urbanizam, kultura, adaptacija

\begin{abstract}
Prijepolje is first mentioned in historical documents in 1332, and it is mentioned by the travel writer and diplomat Adam Guillaume, writing about old towns and mining places. However, Prijepolje appears for the first time in the available written monuments in the contract that the people of Dubrovnik concluded on July 7, 1343 with Arbanasi Burmazi about the transfer of 100 loads of salt to the square of the Milesevo monastery in a place called "Prijepolje". "The development of Prijepolje as a square was significantly contributed, among other things, by its favorable geographical position at the intersection of roads from the Lim valley through Sjenica and Trgovište towards Novo Brdo, Pristina, Trepca, and further towards Sofia and Istanbul." The second part of the road went through Visegrad, Gorazde, Foca to Dubrovnik. Prijepolje was not just a caravan station in the classical sense, that is, a place of lodging and rest for people and horses after a hard journey. Merchants and proud people met there, various trade activities were performed and contractual amounts were paid for various transfers of goods [5].
\end{abstract}

Keywords: history, urbanism, culture, adaptation

\section{NAPOMENA:}

Ovaj rad proistekao je iz master rada čiji mentor je bio prof. dr Darko Reba.

\section{UVOD}

Tema istraživanja, kao i zadatak ovog rada, temelji se na znanstvenim istraživanjima koja imaju za cilj prikazati grad Prijepolje u transformacijama kroz istorijske, socijalne, kulturne i urbane etape i adaptaciju Nacionalnog parka heroja.

\section{Ime grada i geografski položaj}

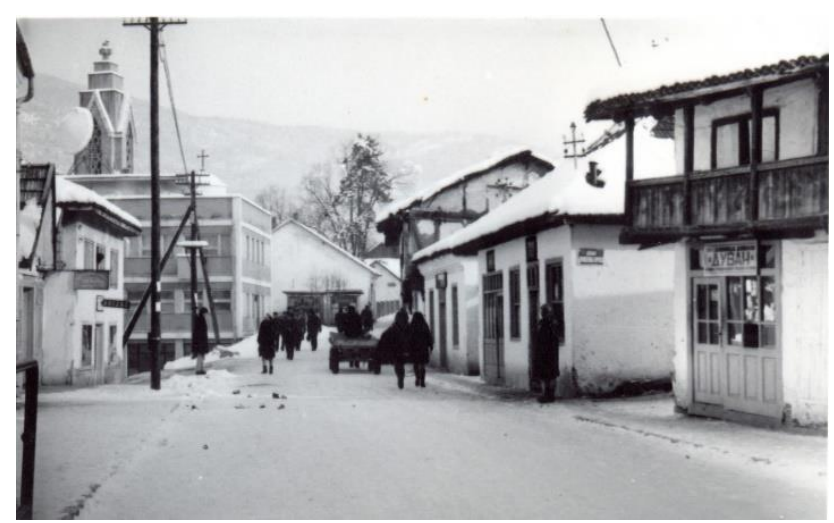

Slika 1. Prijepolje krajem XVII veka-iz arhive Muhameda Hašimbegovića

Niko pouzdano ne zna kada je prvi put izgovoreno i usvojeno ime Prijepolja, kada je u narodu zaživelo. I baš to čudesno ime jednog grada krije u sebi različita tumačenja, razapeta na struni između istorije i legende.

Najverovatnije je da je Prijepolje dobilo ime po starom nazivu muškog imena iz srednjeg vijeka: Prijo - Prija, od kojih je jedan i bio vlasnik Polja gdje su se spajali dubrovački put sa juga sa starobosanskim, koji je dolinom Lima dolazio sa severozapada.

Po vlasniku polje se nazivalo kao Prije Polje ili Polje od Prije, Polje vlasništvo Prije ili Prija. Otuda i naziv Prijapolje odnosno Prijepolje. Jedna od legendi o postanku grada kaže: ,Sa koje god strane da se prilazi ovom mestu, pre (prije) nego se u njega dođe, naići će se na polje [1]. Ako se dolazi niz Lim, naići će se na Ivanjsko polje, ako se dolazi uz Lim iz pravca Priboja ili Nove Varoši, naići će se na Hašimbegovića polje, a ako se dolazi iz pravca Mileševe, naići će se na polje Luke. Dakle, prije je polje, pa s koje god strane da se dolazi u ovo mjesto.

Objašnjenje putniku namerniku je jasno: prije polje, pa tek onda varoš, grad. Čestom upotrebom i sažimanjem ove dve odrednice nastade ime Prijepolje [2].

Gde se tačno začelo jezgro starog Prijepolja danas se ne može sa sigurnošću utvrditi. 
Istina, u literaturi se nalazi objašnjenje narodnog predanja koje tvrdi da se nekada Prijepolje nije nalazilo tamo gde je ono danas, već u Ivanju, uzvodno uz Lim sa njegove desne strane [3].

Predanje kaže da je tom varoši nekada gospodario neki Ivan-beg po kojem je i varoš dobila ime Ivanje, a koja se posle njegove smrti premestila na današnje mjesto gdje je ranije bilo polje, a kasnije se razvilo u Prijepolje.

Međutim, tu dilemu razjašnjava jedan podatak o prevozu robe iz 1407. godine kojeg navodi Bogumil Hrabak u svom radu ,Poslovni ljudi Prijepolja 1350-1700"[4]. Prema tom dubrovačkom izvodu tačno je naznačen, prevoz robe od Ivanja do Prijepolja, što ukazuje da se radi o dva sasvim različita mesta do kojih je trebalo robu transportovati.

Prijepolje preseca dolina Lima pravcem jugoistok severozapad, sa kojom se povezuje veći broj manjih reka. $\mathrm{Na}$ dodiru reka Lima i Mileševke razvilo se staro Prijepolje.

Prijepolje i njegova okolina su aktivno povezani sa susednim mestima Crne Gore i Srbije. Južno od Prijepolja, dolinom Lima put ide prema Bijelom Polju, udaljenom 55 km i dalje Mojkovcu, Kolašinu, Podgorici i Baru, a severno od Prijepolja prema Bistrici udaljenoj 10 $\mathrm{km}$, gde se put račva u dva smera, jedan prema Priboju udaljenom oko $30 \mathrm{~km}$, a drugi prema Novoj Varoši udaljenoj od Prijepolja oko $27 \mathrm{~km}$ i koji dalje preko planine Zlatibor ide prema Užicu, Požegi, Kosjeriću, Valjevu, Beogradu i drugim mestima.

Zapadno od Prijepolja put vodi dolinom Seljašnice preko planinske visoravni Jabuke prema Pljevljima udaljenim oko $30 \mathrm{~km}$, a istočno od Prijepolja dolinom Mileševke i planine Jadovnik prema Sjenici udaljenoj oko $30 \mathrm{~km}$ i dalje prema Novom Pazaru, Prištini i Skoplju.

\section{ANALIZA POSTOJEĆEG STANJA OPŠTINE PRIJEPOLJE}

Prijepolje je grad u istoimenoj opštini, u Zlatiborskom okrugu, u Srbiji. Nalazi se na ušću reke Mileševke u Lim, u podnožju planine Jadovnik.

U njegovoj neposrednoj blizini je manastir Mileševa i stari grad Mileševac. Tokom Drugog svetskog rata $u$ njemu se vodila bitka za Prijepolje. Grad je od svog postojanja pa do danas menjao svoju urbanu fizionomiju: trg, pazarište, grad islamsko-orijentalnog tipa, grad pod Austrougarskom-izgradnja prvih objekata, potom pad porušavanje istih, poplave, industrijalizacija.

Na slici broj 1. prikazan je svakodnevni život u Prijepolju tokom XVII veka. Danas je Prijepolje smešteno u srcu Polimlja, okruženo planinama, razbijenog je tipa, urbanistički rešeno, ali i žudi za obnovom gotovo svih postojećih lokacija, žedno promena, novina.

\subsection{KRITIČNE LOKACIJE}

Kako je gore već spomenuto, većina lokacija zahteva preuređenje. Nakon anketiranja, ali i tokom analize, dolazim do zaključka da je najneophodnije pozabaviti se sledećim lokacijama koje su prikazane na slici broj 2:

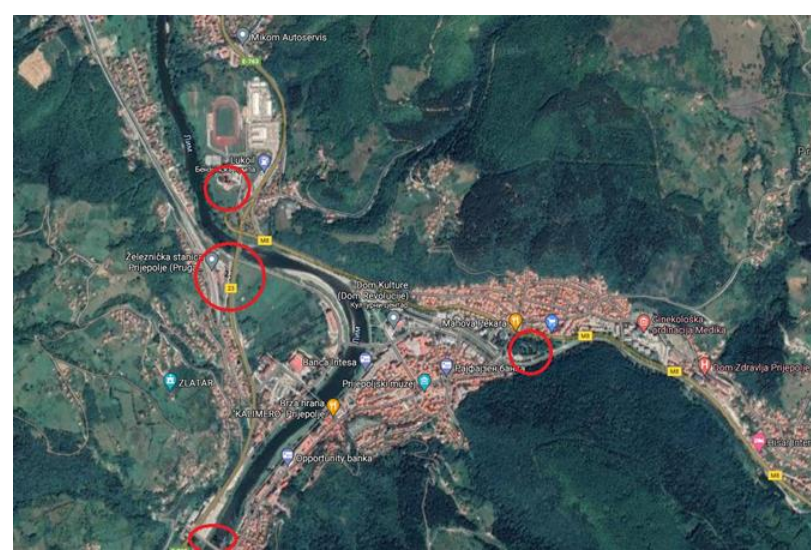

Slika 2. Potencijalne lokacije-izvor: google.com

1. Hotelski kompleks Mileševa sa starim bazenom

2. Železnička stanica

3. park Narodnih heroja

4. Fatihov most

1) Za obnovu hotelskog kompleksa potrebno je planirati potpunu rekonstrukciju i obezbediti enormna finansijska sredstva.

2) Obnova železničke stanice, takođe, zahteva potpunu rekonstrukciju.

3) Parku Narodnih heroja u datom momentu, odgovara adaptacija i obezbeđena su sredstva za realizaciju.

4) U toku je rekonstrukcija. Nekadašnje velelepno izdanje, sačuvalo je jedino masivne stubove, na koje se naslanja ne tako lep most i ograda koja preti da naruši estetiku u potpunosti i izbriše tragove istorije.

\subsection{ZAKLJUČAK ANALIZE POSTOJEĆEG STANJA}

Glavni cilj bio je ispitati kroz koje faze je Prijepolje prolazilo, kako urbanistički, tako i socijalno, ekonomski i kulturološki. Na osnovu detaljne analize, dolazi se do zaključka koji je značaj samog grada, šta je to što treba sačuvati, adaptirati, konzervirati, negovati i održavati. Cilj je sačuvati tradiciju, velelepne i istorijske objekte, očuvati prirodu, razviti turizam, obezbediti neophodan sadržaj na potencijalnim lokacijama i omogućiti pristup svima, a naročito deci.

\section{PREDLOZI REŠENJA U CILJU OSTVARENJA STRATEGIJA}

Vodeći se analizom postojećeg stanja kao i nedostacima koji su zaključeni na osnovu analize, komunikaciji sa građinama, potražnjom finansijskih sredstava od vodećih institucija, sedeća faza rada biće preusmerena na projekat adaptacije parka Narodnih heroja. Naime, park Narodnih heroja, jedan je od dva parka na nivou grada i takođe manje lep, ali lokacijski jako važan i pruža mnoštvo mogućnosti uz minimalne napore.

\subsection{Postojeće stanje}

Park narodnih heroja nalazi se oivičen sa južne i jugoistočne strane rekom Mileševkom sa zapadne strane Ulicom Borak a sa severne magistralnim putem M8 što vidimo na slici broj 3 . 


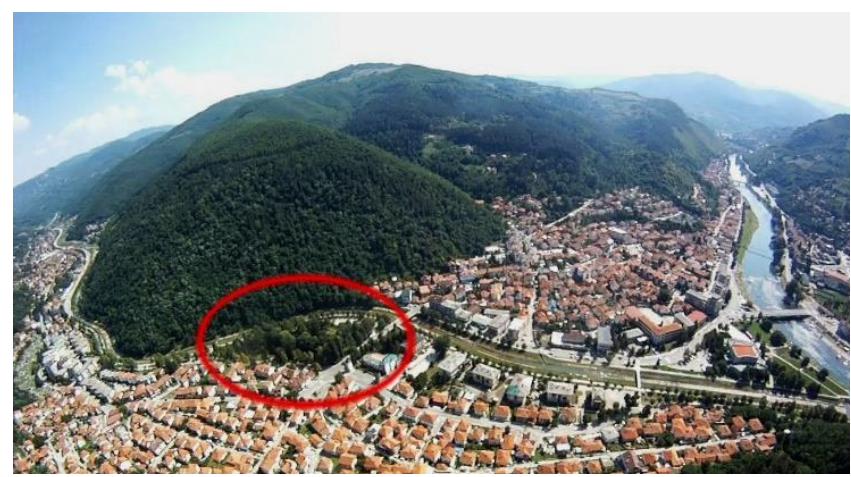

Slika 3. Položaj parka na panorami grada

\subsection{Nivelacija i delovi parka}

Kako je park denivelisan u odnosu na ulice, pristupa mu se sa troje stepenica i to jednim na zapadnom delu u blizini mosta preko Mileševke iz ulice Borak, drugim takođe iz ulice Borak na sredini zapadne širine parka, trećim na samom uglu prko puta sahat kule i četvrtim na zapadnoj strani sa magistralnog put M8. Ova saobraćajnica pada nivelaciono ka istoku, te se na samom ćošku parka utapa u niveletu obale Mileševke.

Ovo je ujedno i prvi veliki problem za sve one koji decu izvode u šetnju u kolicima ili za osobe koje su invalidi, jer za spuštanje na nivo parka ne postoje rampe.

Prostor parka je podeljen na nekoliko celina i nivoa, koji uopšte nisu povezani rampama te je komunikacija između njih otežana.

Centralni deo paka (N1) formiran je oko spomnika četiri narodna heroja, odakle sa staze šire u raznim paravcima.

$\mathrm{Na}$ tom nivou do samih škarpi, koje resavaju denivelaciju izmedju ulica i ovog dela parka, nalaze se otvoreni kanali, prikazani na slici broj 4., za drenažu površinskih voda kojima se odvod u Mileševku. Ovakvi otvoreni kanali su bili i jesu opasnost za mnoge, pogotovo decu koja u njih lako neoprezom upadnu i povrede se. Noću, takođe, predstavljaju veliku opasnost po bezbednost ljudi i dece.

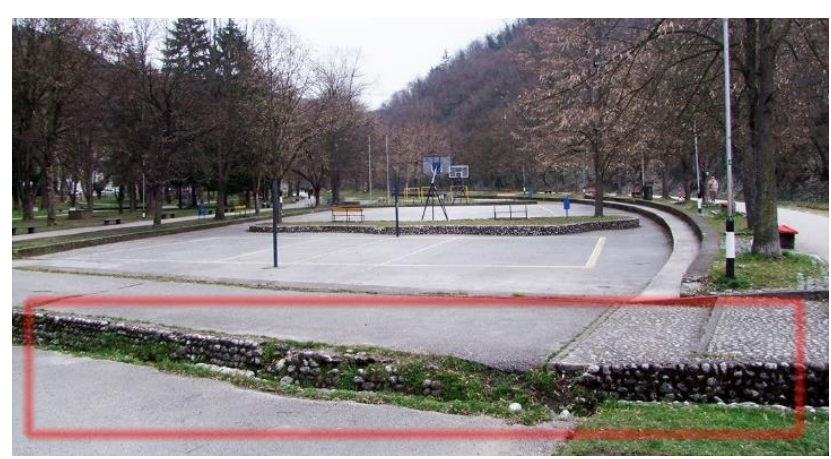

Slika 4. Otvoreni kanali

Sportski tereni i igralište za decu (N2) su još više

denivelisani u odnosu na deo parka gde je spomenik ali i u odnosu na nivo staze kraj Mileševke.

Svi ovi nivoi su takođe bez pristupnih rampi i bez poprečne veze, pa se korisnici parka kreću travom u svim željenim pravcima.

\section{Šetalište pored Mileševke (N3)}

Staza pored reke prati blagi luk uređenog korita i drvored kao na slici broj 5. Predstavlja najupečatljiviji deo pros- tora kako zbog reke tako i zbog pogleda na šumoviti predeo preko puta.

Nedostatak prostora je nedovoljan broj klupa, nemanje bočnih veza sa ostalim delom parka, velike denivelacije platoa korita reke koji su zatravljeni i takođe mogu da se koriste za šetalište ili odmor na travi. Postojeće stanje parka kao na slici broj 6 .

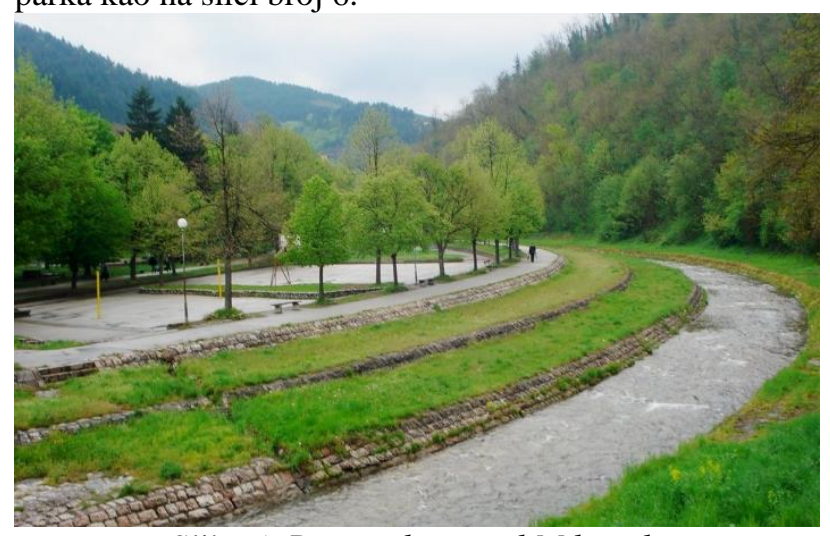

Slika 5. Deo parka pored Mileševke

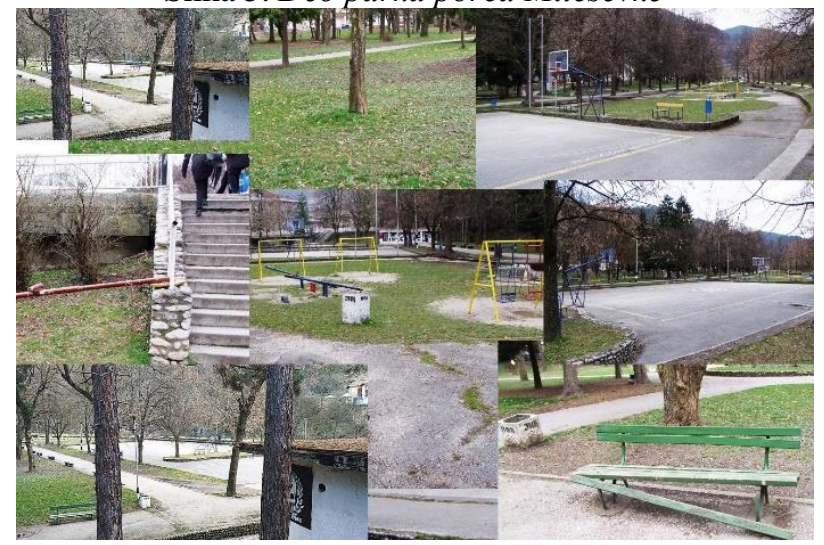

Slika 6. Fotografije postojećeg stanja

\subsection{Drveće i zelenilo}

Park poseduje veoma kvalitetno, visoko i zdravo drveće ali postoje i delovi parka koji bi mogi da se obogate novim sadnicama drveća i žbunastih vrsta zelenila, za šta je potrebno uraditi projekat valorizacije posotojećeg zelenog fonda i predlog hortikulturnog uređenja.

Travnjaci su u pristojnom stanju ali bi mogli da se obnove, kao i da se formiraju cvetne aleje na pojedinim pravcima.

\subsection{Planirane intervencije}

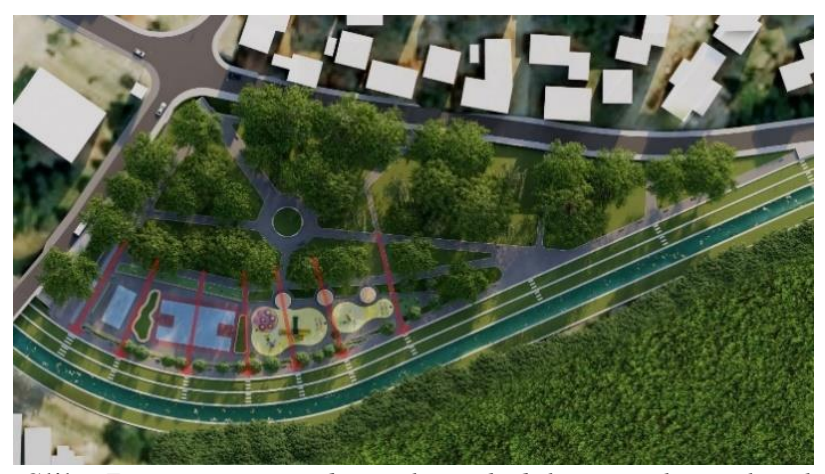

Slika 7. Povezivanje denivelisanih delova parka i izlazak na reku 


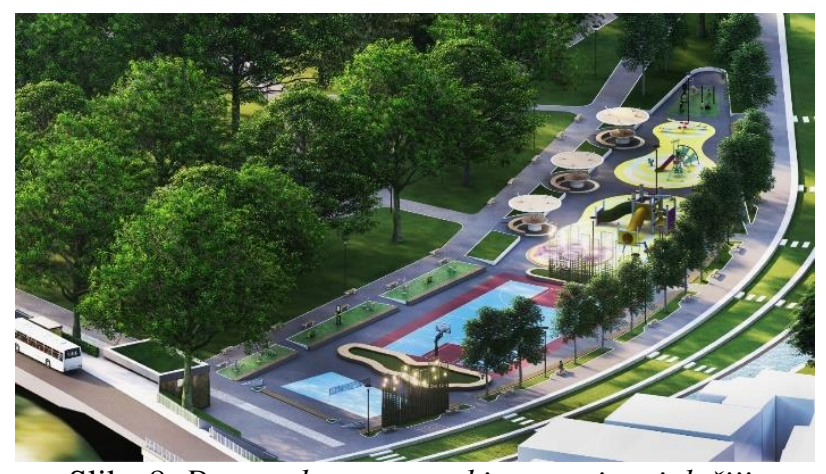

Slika 8. Deo parka sa sportskim terenima i dečijim igralištem

Ovi tereni se mogu obeležavanjem prilagoditi za više sportskih namena kao na slici broj 8 .

Jedan od problema koji se javlja sadašnjom upotrebom je i odlazak lopte van terena usled nepostojanja mreža. Po pravilu bi ceo prostor trebalo ograditi visokim mrežama, ali bi to umnogome naružilo prostor, pa smo pribeli jednoj ideji koji ima tu funkciju ali je vizelno potpuno uklopljena u ambijent. Radi se ramovima sa inox mrežom koji se postavljaju iza intezivne zone putanja lopte (koševi, golovi) kao na slici broj 9.

Sa zadnje strane bi se pustile puzavice koje bi za par godina stvorili veoma lepu vertikalnu zelenu površinu. Naizmeničnim svetlima u samoj mreži bi se simulirala silueta grada.

Denivelacije koje su okolo terena su savladane rampama i stepenicama, tako da se nesmetano može među njima komunicirati prikazano na slici broj 7 .

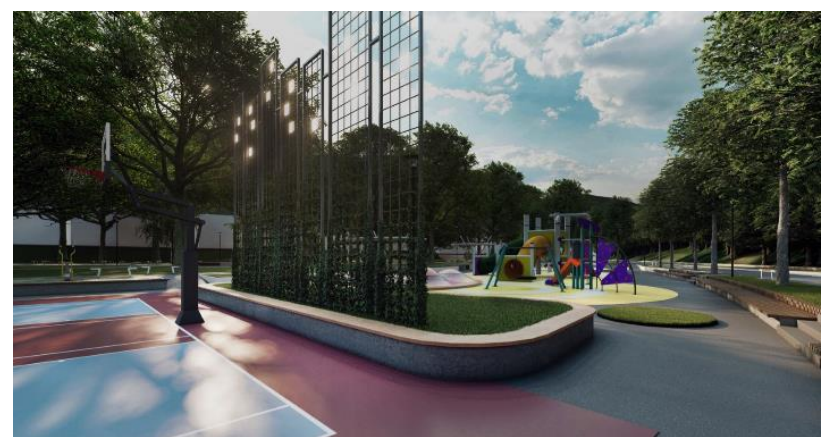

Slika 9. Uređenje sportskih i dečijih igrališta, postavljanje zaštitne mreže i oblaganje zidića drvenim gredicama

\section{ZAKLJUČAK}

Kao što se može videti na slici broj 10. predložene strategije podrazumevaju projektovanje novih funkcionalnih i estetskih sadržaja namenjene deci i odraslima, omogućavajući pristup osobama sa invaliditetom, majkama sa decom u kolicima, starijim osobama.

Takođe, promena utiče pozitivno na pokretanje drugih mnogih aktivnosti, utiče na jedinku koja integriše sa drugima i zajedničkim delovanjem menja prostor i oplemenjuje ga.

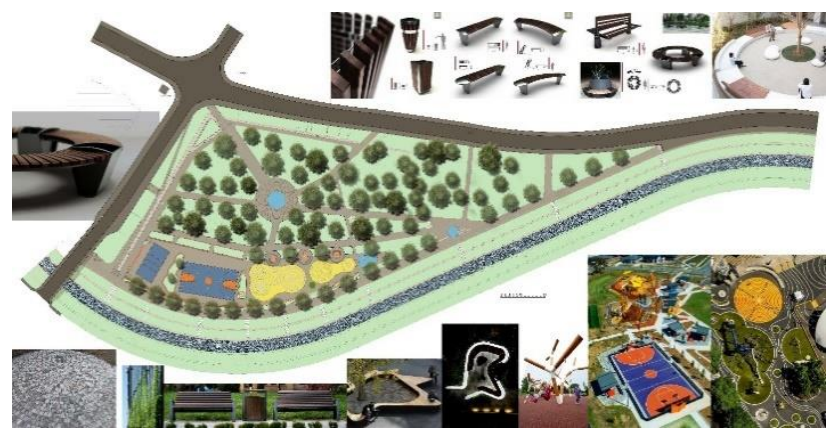

Slika 10. Koncept parka

Ovom prostoru je posvećena posebna pažnja, jer deca su najosetljiviji deo populacije, a njihov fizički i mentalni razvoj je veoma bitan.

Preterana zaštita dece u poslednje vreme dovela da njihove funkcije nisu adekvatno razvijena $\mathrm{i}$ da je deci veoma bitno da razviju veštine penjanja, balansiranja, da osete i deo straha kad naprave pogrešan potez, čak i da padnu, jer je sve to proces učenja, odrastanja, razvijanja motorike, učenja savladavanja prepreka. Savremeni propisi su sasvim jasno definisali te granice koje neće ugroziti decu, a opet im dati prostor da iskuse avanturu.

\section{LITERATURA}

[1] Femić, Mr. Milinko, Prijepoljski kraj u prostoru i vremenu, Beograd-Prijepolje, 1999.

[2] Rovčanin, Arif, Ime tvoje i moje, Prijepolje, 2008

[3] Barjaktarević, Dr. Mirko, Prijepolje, zbornik filozofskog fakulteta, IV-1, Beograd, 1956.

[4] Bogumil Hrabak, Poslovni ljudi Prijepolja 1350-1700.

Simpozijum Seoski dani Sretena Vukosavljevića III,

[5] Mulić, Jusuf, Hercegovina 1, Sarajevo 2004

\section{Kratka biografija:}

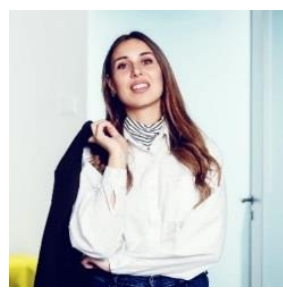

Šejla Rondić rođena je u Prijepolju, 1995. godine. Osnovne akademske studije završila je na Državnom univerzitetu u Novom Pazaru, 2019. god.Master akademske studije odbranila na Fakultetu tehničkih nauka u Novom Sadu 2021.godine.

\section{Kontakt: sejlar95@gmail.com}

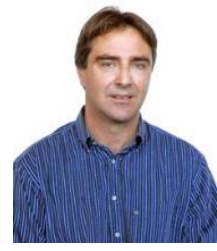

Prof. dr Darko Reba (1968) je redovni profesor na Departmanu za arhitekturu i urbanizam na Fakultetu tehničkih nauka u Novom Sadu. Diplomirao je 1995.na Arhitektonskom fakultetu u Beogradu, magistrirao 2001. i doktorirao 2005. na Fakultetu tehničkih nauka u Novom Sadu.

Kontakt: rebad@uns.ac.rs 